\title{
Fala e escrita de gírias: análise, descrição e possibilidades em sala de aula
}

\author{
Speech and slang writing: analysis, description and possibilities in the \\ classroom
}

Habla y escritura de jerga: análisis, descripción y posibilidades en el aula

\author{
Daniel da Rocha Silva ${ }^{1}$
}

\begin{abstract}
Resumo
O presente trabalho traz uma análise acerca de gíria, passando pela sua exclusão (ou tentativa) até a sua contribuição para o ensino de Língua Portuguesa em sala de aula. A fundamentação teórica baseia-se em Bagno (2006 e 2009), Marcuschi (2007), Castilho (2009), dentre outros; além de ressaltar os documentos orientadores: LDB (1996) e PCN (1998). O ensino de língua deve ser debatido, não colocando as regras gramaticais como únicas, mas trazendo a variedade linguística do aluno para o centro do debate e, consequentemente, inseri-lo na construção do conhecimento, este passando pelo questionamento.
\end{abstract}

Palavras-chave: gíria; fala e escrita; ensino e aprendizagem; sala de aula.

\begin{abstract}
This paper brings an analysis about slang, from its exclusion (or attempt) to its contribution to the Portuguese Language teaching in classroom. The theoretical framework is based on Bagno (2006 and 2009), Marcuschi (2007), Castilho (2009), among others, besides highlighting the guidelines: LDB (1996) and PCN (1998). Language teaching must be debated, not placing grammatical rules as unique but bringing the students language variety to the center of the debate and, consequently, inserting it in the construction of knowledge, this through questioning.
\end{abstract}

Keywords: slang; speech and writing; teaching and learning; classroom.

\section{Resumen}

El presente trabajo trae un análisis de jerga, pasando por su exclusión (o intento) hasta su contribución a la enseñanza de Lengua Portuguesa en el aula. La fundamentación teórica es basada en Bagno (2006 y 2009), Marcuschi (2007), Castilho (2009), entre otros; además de resaltar a los orientadores: LDB (1996) y PCN (1998). La enseñanza de lengua debe ser debatida, no colocando las reglas gramaticales como únicas, pero trayendo la variedad lingüística del alumno al centro del debate y, consecuentemente, insertarlo en la construcción del conocimiento, éste pasando por el cuestionamiento.

Palabras-claves: jerga; habla y escritura; enseñanza y aprendizaje; el aula.

\footnotetext{
${ }^{1}$ Graduado em Letras Vernáculas - FISE; Especialista em Educação Especial e Inclusiva - FAJAR; Pósgraduando em Linguística Aplicada na Educação - Instituto Graduarte; Pós-graduando em Tecnologias e Educação Aberta e Digital - UFRB. E-mail: danieldarochasilva@gmail.com.
} 


\section{Introdução}

"Nenhum dos estados atingiu os resultados adequados em língua portuguesa e em matemática 2", diz a manchete no site da Revista Época ao se referir aos resultados do IDEB (Índice de Desenvolvimento da Educação Básica) de 2015, que apresentou uma média de 4,5 nos anos finais do ensino fundamental, portanto, abaixo da meta prevista pelo governo. A deficiência presente no ensino e aprendizagem de Língua Portuguesa confirma-se no desempenho pífio de estudantes em exames, sejam governamentais ou não; ainda, agravado pela falta de interesse cada vez mais notável em aprender a Língua Portuguesa decorando regras. Dito isto, faz-se necessária mudanças metodológicas que possam fazer com que traga o entusiasmo do aluno para gostar de aprender, saindo da obrigatoriedade, outro fator, que tem desestimulado o alunado. A Lei de Diretrizes e Bases para a Educação - LDB (Lei $n^{o}$ 9.394, de 1996) defende toda heterogeneidade que reflita no pensar através de diferentes formas de linguagem e ensinar com diferentes formas de fazer aprender: "III - pluralismo de ideias e de concepções pedagógicas" (p. 1, 1996), subjaz, diversos métodos que aprimorem o ensino de língua. O objetivo não é defender uma substituição do que está posto, mas trazer um debate nos métodos de ensino e aprendizagem com capacidade de inserir a gíria em uma discussão construtiva acerca do funcionamento da língua pois a gramática normativa, o livro didático, o quadro e o giz são relevantes e tornaram-se peças culturais quando nos referimos ao ensino e aprendizagem, porém, esse conjunto não é mais único em sala de aula.

Não há "imobilidade absoluta", conforme Saussure (2006, p. 163), mesmo este defendendo o estruturalismo. Então o que se presencia é a gramática sendo apresentada como a detentora do que realmente é a língua, isto é, regras a serem seguidas. Ela (gramática) tem a sua devida importância dentro do ensino e aprendizagem, porém, como ela está sendo e/ou vem sendo passada é que precisa ser mudado, pois já demonstrou precariedade através do método tradicional. Vê-se uma didática pouca (ou nada) inovadora, na qual o aluno deve decorar a regra para a prova, e um dia após esta, esquece-a. Concomitante, o professor não deve taxar como errada a variedade linguística do aluno, ele deve apresentar os diversos conceitos que demonstrem as variedades linguísticas e suas diversas formas de comunicabilidade, seja através de textos escritos ou orais, pois a gíria é uma variedade passiva de comunicabilidade, ou seja, entendem-se uns aos outros independente do dialeto de sua oralidade; assim como todas as outras: regionalismos, jargões. $\mathrm{O}$ diferencial é fazer com que o

2 Disponível em: <https://epoca.globo.com/vida/noticia/2016/09/ensino-medio-mais-uma-vez-tem-piorresultado-do-ideb.html> Acesso em: 04 set. 2018. 
aluno compreenda que a linguagem é mutável, e exige do falante uma adaptação de acordo com cada situação vivida.

A gíria é uma variação linguística presente na fala do aluno, e até mesmo do professor, visto que, conforme Bagno (2009), não falamos a norma padrão o tempo inteiro, até mesmo quem teve acesso a este. O preconceito instaurado na linguagem ainda faz com que o profissional de ensino corrija o discente dentro da sala de aula, impedindo a participação do mesmo. Contudo, deixa de perceber na oralidade do aluno uma matéria para ensinar tanto sintaticamente quanto para fazer uma análise semântico-pragmática acerca da constituição significativa das palavras comparando-as com os fragmentos textuais de escritores puritanos.

\section{Gíria e sua exclusão}

Presente no dialeto quase que, impreterivelmente, do indivíduo, a gíria caracteriza-se pela espontaneidade no sentido de que ela não tem regra e, por ser, conforme Preti (2006), um vocábulo que se apresenta na fala. A gíria não está presente em gramáticas normativas possibilitando análises sintáticas sobre estas. Por isso, também, essa sua especificidade que a envolve em um conceito de aleatoriedade. Porém, quando nos referimos à gíria, o senso comum já nos remete à oralidade de pessoas marginalizadas que, raramente, não estão envolvidas em situações ilícitas, pois, como bem afirma Patriota (2004), essa relação é histórica, e segundo a autora, a gíria representa um: "Vocábulo típico da linguagem oral, [...], desde seus primeiros representantes - mascates da Idade Média - é ligada diretamente aos grupos marginalizados e excluídos da sociedade" (PATRIOTA, 2004, p. 53). Fato este que trouxe um estereótipo depreciador a essa variedade do português brasileiro que acaba interferindo e até mesmo impossibilitando um trabalho sobre tal linguagem em sala de aula, embora algumas já tenham sido dicionarizadas. Contudo, as acepções encontradas em dicionários que circulam no Ensino Fundamental II são ignorantes, justamente por classificar os grupos sociais que a utilizam, disseminando, com isso, o preconceito linguístico.

O Mini Aurélio: o dicionário da Língua Portuguesa (2010, p. 379) define gíria como: "sf. 1. Linguagem de malfeitores, malandros, etc", ou seja, descrição que só enaltece o preconceito, sendo que é essa a linguagem encontrada na oralidade de maioria dos alunos do ensino fundamental II, principalmente das séries iniciais quando ainda não conseguem compreender o (s) motivo (s) de tal acontecimento; na segunda acepção, o Aurélio descreve: "2. Linguagem que, nascida em certo grupo social, termina estendendo-se à linguagem 
familiar" (ibidem), percebe-se uma tentativa de restrição linguística que leva o leitor comum a entender por "certo grupo social" como algo que exige distanciamento, por ser perigoso, nocivo. Em virtude do que já foi dito, subjaz que a tentativa de unidade da linguagem pretendida pelos defensores da gramática tradicional é advinda da própria história do Brasil que, outrora, é contada pela desigualdade que norteia e afeta quaisquer princípios, ao ponto de delimitar uma variedade da linguagem e caracterizá-la preconceituosamente. Os Parâmetros Curriculares Nacionais (1998, p. 17) confirmam: “ [...] tais propostas se restringiam aos setores médios da sociedade, sem se dar conta das consequências profundas que a incorporação dos filhos das camadas pobres implicava", entende-se que as estratégias de ensino e aprendizagem visaram uma determinada classe social que já tinha uma base, da família, do que iriam ver na escola. Apesar das mudanças no contexto escolar, ainda se mantém traços característicos, especificamente, no ensino de Língua Portuguesa. E se o indivíduo não teve acesso ao dito "padrão"? Como exigir que ele o utilize? As gírias trazem em si a comunidade do falante e é capaz de identificar a sua classe social e esta última, é a responsável pela exclusão na linguagem, pois:

A maleabilidade do sistema linguístico produzida pelo mecanismo da variação linguística permite que a língua capture em sua configuração estrutural as diversas nuanças das diferenças sociais, de modo que dialeticamente não é possível compreender a configuração estrutural de uma língua como fenômeno sóciohistórico sem compreender a história e a configuração da sociedade em que essa língua é falada (LUCCHESI, 2015, p. 34)

O Minidicionário Escolar de Língua Portuguesa enfatiza: "gíria: S.f. 1. Língua especial, cifrada, usada por marginais" (RIOS, 2008, p. 257), conceituações deste tipo não salientam que a gíria está presente na oralidade de pessoas que não se encaixam neste contexto social, pois a mesma encontra-se: na fala dos jogadores de futebol, de artistas business, cantores de rap, sendo que algumas dessas pessoas acumulam fortunas com seus trabalhos, honestamente. As vozes que representam o rap, por exemplo, fazem nuances impressionantes com a linguagem, inclusive com o uso de gírias em suas composições, e são verdadeiras obras que proporcionam aos seus ouvintes e/ou leitores um pensamento crítico, muito em decorrência dessa linguagem simples de ser compreendida e que permite ao sujeito sentir-se representado por esta linguagem, pois é a mesma que ele fala, como bem afirma Bagno (2006, p. 15): "É o português de uma classe social diferente da nossa, só isso".

\section{Gíria: um auxiliar metodológico para o ensino de Língua Portuguesa}


Os Parâmetros Curriculares Nacionais (1998) tentam remontar o ensino baseandose no domínio da leitura e da escrita por parte dos alunos, no entanto, esse pensamento já advém da década de 80, porém, ainda não está consolidado. Esse norteador de comportamento profissional permite ao professor o uso de metodologias variadas de ensino, como podemos observar na citação seguinte:

Ao professor cabe planejar, implementar e dirigir as atividades didáticas, com o objetivo de desencadear, apoiar e orientar o esforço de ação e reflexão do aluno, procurando garantir aprendizagem efetiva. Cabe também assumir o papel de informante e de interlocutor privilegiado, que tematiza aspectos prioritários em função das necessidades dos alunos e de suas possibilidades de aprendizagem (BRASIL, 1998, p. 22)

Isto é, possibilita ao docente mesclar os métodos e que deixem a sua aula atrativa. A gíria é uma matéria-prima presente na oralidade do aluno em sala de aula e que poderia ser aproveitada pelo professor com o objetivo de demonstrar os processos constitutivos e constituintes da linguagem, pois " $\mathrm{O}$ objeto de ensino e, portanto, de aprendizagem é o conhecimento linguístico e discursivo com o qual o sujeito opera ao participar das práticas sociais mediadas pela linguagem" (BRASIL, 1998, p. 22). Infelizmente, o professor continua a corrigir o aluno diante dos demais, taxando a sua variedade de errada, fato que inibe a participação da classe estudantil dentro da sala de aula com comentários que poderiam agregar ao conhecimento de ambos. A frase, a seguir, foi proferida por um aluno em sala de aula:

\section{(1) Pense na talarica que eu tô}

(Fonte: o Autor, nov. de 2016)

Nesta oração, o que chama a atenção é a palavra talarica, que quer dizer fome. É um léxico compreensível e que não interfere no sentido do enunciado, visto que, no contexto, o falante sinaliza com a mão na barriga. A oralidade não traz vocábulos sem conteúdo, “ [...] entre oralidade e escrita não existem diferenças quanto aos conhecimentos que podem ser por elas transmitidos ou gerados" (MARCUSCHI, 2007, p. 47). Ainda, permite uma análise sintática:

\section{(2) Pense na talarica que eu tô}

(Fonte: o Autor, nov. de 2016)

- Têm-se duas orações, por conter dois verbos: "PENSE" e "TÔ", este último sendo o verbo de ligação ao sujeito "EU"; "NA TALARICA", funciona como predicativo do sujeito. 
É uma metodologia que o professor não explora e continua a repassar o que está posto sem nenhum questionamento, trazendo antipatia à gramática normativa que tem resultado em desempenhos ruins dos estudantes nas avaliações de linguagens. Está-se preso a um tradicionalismo que está desgastado e não tem trazido o efeito esperado. Preti (1974) chama a atenção para este conceito que se tem quando nos referimos à escola, de tradicional, baseada na seletividade:

A escola é um organismo tradicional por excelência, em termos da língua. Ela procura uma uniformização, tendo por base os níveis mais altos da linguagem, retratados, em geral, nos grandes escritores. Divulga uma norma culta e seu objetivo principal é a língua escrita (no que se refere, é claro, à língua nacional), através da qual se estabelecem padrões linguísticos mais elevados, que, supõe-se, possam vir a influir sobre os hábitos individuais, à medida que os locutores elevem seu grau de instrução. (PRETI, 1974, p. 33)

Historicamente, os locais de ensino sempre trouxeram uma visão de separação entre o que lá se produz e o que está fora; este (fora) representa a comunidade como um todo, e essa visão se torna uma incongruência, visto que a própria escola e o aluno estão na sociedade e fazem parte desta como construtores. Desde sempre, quando o mesmo adentra à escola, é uma prescrição de que ele deve esquecer o que ele traz de lá de fora, de sua vivência social, de seu conteúdo, de sua linguagem. A partir de então, há esse confronto entre a realidade do aluno e a realidade que a escola quer que ele tenha.

Mesmo com as deficiências notáveis de aprendizagem e a orientação da $L D B$ (1996) e dos PCNs (1998) para possibilidades de mudanças metodológicas, pouco foi mudado. Temse, ainda dentro desse tradicionalismo, uma ideia formada de que tudo que a oralidade produz é desconexo, inviabilizando o que seria uma inserção do aluno na construção de seu próprio conhecimento. Marcuschi $(2007$, p. 47) ressalta que " [...] a passagem da fala para a escrita não é a passagem do caos para a ordem: é a passagem de uma ordem para outra ordem”, porém, esbarra nos preconceitos sociais.

A seguir, veremos uma tabela com algumas gírias presentes na oralidade dos alunos em sala de aula:

Tabela 1: Gíria vs. Padrão

\begin{tabular}{|c|l|}
\hline SAQUE & OLHAR, OBSERVAR \\
\hline TRUTA & IRMÃO \\
\hline TALARICA (LARICA) & FOME \\
\hline PAIA & RUIM \\
\hline
\end{tabular}


RELACult - Revista Latino-Americana de Estudos em Cultura e Sociedade

\begin{tabular}{|c|l|}
\hline VACILÃO/MOSC ̃̃O & ALGUÉM QUE ERROU \\
\hline BORÓ & CIGARRO \\
\hline
\end{tabular}

Fonte: o Autor (nov. 2016) ${ }^{3}$

Mesmo Saussure não relacionando a sua teoria com o meio, ele foi crucial em uma de suas descrições ao definir a língua como: “ [...] o conjunto dos hábitos linguísticos que permitem a uma pessoa compreender e fazer-se compreender" (SAUSSURE, 2006, p. 92). Portanto, a gíria se insere neste contexto no qual quem a fala entende e é entendido.

Contudo, a inserção direta da gíria no ensino em sala de aula permite ao professor uma dinâmica de trabalho na qual o mesmo terá a oportunidade de trabalhar a variedade linguística de seus alunos com propostas criativas e atrativas, sugerindo que textos sejam escritos usando a espontaneidade da fala de cada um, consequentemente, propor uma transcrição para o padrão, ainda, um transcrevendo o do outro e, assim, mostrando que a linguagem se apresenta de várias maneiras, todas elas dotadas de relevância. As várias possibilidades de uso da linguagem são chamadas pelos $P C N$ (1998, p. 23) de "competência discursiva", visto como um saber, e é conceituado como: "Um dos aspectos de competência discursiva é o sujeito ser capaz de utilizar a língua de modo variado, para produzir diferentes efeitos de sentido e adequar o texto a diferentes situações de interlocução oral e escrita".

Demonstra que se precisa ter uma formação que esteja de acordo com a evolução dos fatos, pois não é possível ignorá-los visto que o indivíduo se relaciona com a sociedade em diversas instâncias que vai desde uma conversa formal entre dois advogados a uma conversa entre estes e um cliente que não teve acesso à norma culta, necessitando uma adaptação da linguagem para que esse último entenda o que está sendo dito.

\footnotetext{
A importância e o valor dos usos da linguagem são determinados historicamente segundo as demandas sociais de cada momento. Atualmente, exigem-se níveis de leitura e de escrita diferentes dos que satisfizeram as demandas sócias até há bem pouco tempo - e tudo indica que essa exigência tende a ser crescente. A necessidade de atender a essa demanda, obriga à revisão substantiva dos métodos de ensino e à constituição de práticas que possibilitem ao aluno ampliar sua competência discursiva na interlocução. (BRASIL, 1998, p. 23)
}

A língua não é estática, no entanto, parou em sua representatividade maior: a gramática normativa. É um ensino que não permite ao aluno descrições próprias, apenas copiar e tentar compreender tantas tipificações e suas exceções.

\footnotetext{
${ }^{3}$ Fonte: o Autor, nov. 2016. Gírias faladas por alunos do 6 ano "C", da Escola Municipal de Ensino Fundamental Nicodemos Correia Falcão. Tobias Barreto - SE.
} 


\section{Considerações finais}

O problema é histórico, tem um caráter social marcado pela divisão de classes, são fatores que repercutem na língua com capacidade de estereotipá-la. Em meio a tudo, o professor não tem como obrigatoriedade seguir a gramática normativa e o livro didático como únicos meios de metodologia de ensino, ele deve abrir espaços para acompanhar a dinâmica, muito em decorrência da contemporaneidade em que estamos envolvidos, pois senão o próprio corre o risco de estereotipar-se ultrapassado. A escola não acompanhou a evolução linguística didaticamente e a gramática está inerte com apenas mudanças de acordos ortográficos, que são lentos e de caráter político; e, ainda, não se remetem a mudanças em decorrência da oralidade dos falantes. Com tantos empecilhos que fogem à individualidade, o profissional de ensino aplica uma resistência a possíveis métodos de aprendizagem inovadores, e percebe-se neste prisma, um receio em perder o espaço, fato que também ocorre na implementação de tecnologias educacionais. O professor e a escola jamais serão substituídos, tamanha a sua importância para uma sociedade pensante. O que se propõe são inovações que acompanhem as mudanças linguísticas visto que os alunos se encontram nestas enquanto sociedade: em casa, na rua, com os amigos, etc. Deve-se compartilhar com Castilho (2009, p. 22) a afirmação de que: “A aula de gramática deve implicar numa atuação participante de professor e alunos, movidos pelo desejo da descoberta científica”, portanto, são complementares um ao outro e não substituições.

As novidades linguísticas não podem ser pensadas como obstáculos que impedem o conhecimento da norma culta e/ou causariam (ou causam) um aglomerado de línguas perdidas e todas elas sem sentido. A variedade linguística deve ser vista como fenômeno do processo civilizatório caracterizado pela contemporaneidade decorrente da evolução humana, que é natural.

A resistência por parte de alguns professores em trabalhar com o novo acaba impedindo a descoberta de uma metodologia que faça com que o aluno construa seus conhecimentos. “(2) Insisto em que a gramática não é o lugar das certezas absolutas, e em classe não devemos transformar nossa capacidade de reflexão para o autor de uma gramática [...]" (CASTILHO, 2009, p. 22), mas é o que tem sido feito. Um ensino que impõe limita a capacidade construtiva do aluno em formular seus próprios questionamentos causando uma deficiência notória na formação do indivíduo. 


\section{Referências}

ARAÚJO, Gisele Santos; SOUSA, Marcus Roberto de Araújo. Gírias, Códigos Linguísticos como Afirmação e Identidade de um Grupo: uma análise e reflexão da possibilidade de uso no ensino e aprendizagem da língua portuguesa. Revista Científica Semana Acadêmica.

Fortaleza, ano MMXVI, No. 000081, 04/03/2016. Disponível em:

$<$ http://semanaacademica.org.br/artigo/girias-codigos-linguisticos-como-afirmacao-eidentidade-de-um-grupo-uma-analise-e-reflexao-da> Acesso em: 03 out. 2016. (Artigo em Periódico Digital)

BAGNO, Marcos. A língua de Eulália: novela sociolinguística. 15 ed. São Paulo: Contexto, 2006. 215 p. (Obra Completa)

. Preconceito Linguístico: o que é, como se faz. 52. ed. São Paulo: Loyola, 2009. 207 p. (Obra Completa)

BRASIL. Secretaria de Educação Fundamental. Parâmetros Curriculares Nacionais: terceiro e quarto ciclos do ensino fundamental: Língua Portuguesa. Brasília: MEC/SEF, 1998. 106 p. (Portaria em Periódico Físico)

. Lei de Diretrizes e Bases da Educação. Lei no 9.394, de 20 de dezembro de 1996.

31 p. (Portaria em Periódico Físico)

CASTILHO, Ataliba T. de. A Língua Falada no Ensino de Português. 7 ed. São Paulo: Contexto, 2009. 158 p. (Obra Completa)

FERREIRA, A. B. de H. Mini Aurélio: o dicionário da língua portuguesa. Coord. Marina Baird Ferreira. 8. ed. ver. atual. Curitiba: Positivo, 2010. 960 p. (Acepção de Dicionário) LUCCHESI, Dante. Língua e Sociedade Partidas: a polarização sociolinguística do Brasil. São Paulo: Contexto, 2015. 320 p. (Obra Completa)

LUDKE, Menga; ANDRÉ, Marli E. D. A. Pesquisa em Educação: abordagens qualitativas. 2. ed. Rio de Janeiro: E.P.U., 2013. 112 p. (Obra Completa)

MARCUSCHI, Luiz Antônio. Da Fala para a Escrita: atividades de retextualização. 8 ed. São Paulo: Cortez, 2007. 133 p. (Obra Completa)

PATRIOTA, Luciene Maria. A gíria nos livros didáticos de Língua Portuguesa do Ensino Fundamental. Graphos - Revista da Pós-graduação em Letras - UFPB. João Pessoa, vol. 6, N. 2/1, 2004. p. 51-64. Disponível em: < http://www.periodicos.ufpb.br/index.php/graphos/article/viewFile/9534/5182> Acesso em: 05 set. 2018.

PRETI, Dino. Sociolinguística: os níveis de fala, um estudo sociolinguístico do diálogo literário. São Paulo: Editora Nacional, 1974. 181 p. (Obra Completa)

. A Gíria na Língua Falada e na Escrita: uma longa história de preconceito social.

In: PRETI, Dino et al (org.). Fala e Escrita em questão. São Paulo: Associação Editorial Humanitas, 2006. 257 p. (Capítulo de Livro) 
RIOS, D. R. Minidicionário Escolar Língua Portuguesa. São Paulo: DCL, 2008. 530 p. (Acepção de Dicionário)

SAUSSURE, Ferdinand de. Curso de Linguística Geral. 27 ed. São Paulo: Cultrix, 2006. 278 p. (Obra Completa) 